ria fielmente traducida al lienzo «y este es cabalmente su mérito, porque el idilio griego es todo sensualidad y monótono erotismo, al paso que la concepción delicada de nuestro pintor es, á la par que erótica, idealista. (...), y veo que la belleza moral ha triunfado de la que sólo inspira deleite y que el pintor ha acertado á idealizar el poético sensualismo de la pastoral griega» ${ }^{29}$.

Creemos, a la vista de lo expuesto, que Pedro de Madrazo no gustó del asunto del cuadro de Reyna Manescau, que para él resultaba un tanto vulgar y escabroso, a pesar de que no contuviese ninguna impudicia figurativa, porque representaba una fiesta licenciosa y disoluta del paganismo romano sustentada básicamente por cortesanas que, aunque pintadas bastante púdicas por el artista, eran, al fin y al cabo, esas meretrices las protagonistas del lienzo. Constituía, por tanto, para Madrazo la antítesis de los otros asuntos clásicos de los cuadros con cuyas críticas lo hemos comparado. No se desprendía del cuadro de Reyna ninguna enseñanza edificante, ningún ejemplo moral. Sin embargo, no le queda más remedio que ceder ante la belleza del lienzo, aunque fuese criticándolo: «paréceme más bien un hermoso compuesto de reminiscencias de obra clásica antigua» ${ }^{30}$. Creemos que el calificativo de «hermoso», aunque sea expresado en un contexto desfavorable al lienzo, delata en el fondo, y a pesar de todo, el buen gusto de Pedro de Madrazo.

Aurora Gil Serrano

Profesora del Instituto Antonio López

(Tres Cantos. Madrid)

\title{
PROCESO INQUISITORIAL CONTRA EL BORDADOR TOMÁS PÉREZ
}

El siglo Xvi fue un período muy brillante para el arte del bordado en Cuenca, sin embargo sabemos muy poco sobre sus artífices, de ahí el interés que tiene el proceso inquisitorial de Tomás Pérez ${ }^{1}$, pues nos permite conocer a uno de aquellos maestros que con su buen hacer contribuyó a que el bordado, principalmente el religioso, adquiriera gran esplendor en Cuenca.

El 17 de agosto de 1571 el clérigo Gonzalo de Cetina ${ }^{2}$, que era descendiente de judíos y en esa fecha residía en El Acebrón (Cuenca), donde desempeñaba su labor como cura párroco, se dirigió al tribunal de la Inquisición de Cuenca solicitando que permitiera a su hermano Isidro de la Muela viajar al Perú, pues quería visitar a un hermano que vivía en Lima, fray Alonso de Cetina, que era agustino. Gonzalo de Cetina para conseguir este permiso tuvo que demostrar que su hermano era cristiano viejo y para ello presentó una serie de testigos, entre los que figuraba el bordador Tomás Pérez, el cual no pudo sospechar entonces que a causa de esta

\footnotetext{
29 Ibidem.

30 Ibidem.
}

1 ADC, Inquisición, leg. 268, n. ${ }^{\circ} 3684$

${ }^{2}$ Pertenecía a una importante familia, cuyos miembros se tenían por «confesos descendientes de tales y que por tales son avidos e tenidos e comunmente reputados en esta ciudad». Entre los antepasados de Gonzalo de Cetina figura Iñigo de la Muela, reconciliado por el Santo Oficio, fue regidor de Cuenca. Ana de Ecija, su bisabuela materna, que estaba casada con Alonso de Guadalajara, el cual «traya un baculo de hordinario en la mano» y vivía «a la baxada de Sancta Maria de Gracia ques en el Alcaçar», en 1512 fue juzgada por el tribunal de la Inquisición por «el delicto y crimen de la heregia y apostasia». También sus hermanos Hernán Gómez de Ecija y Violante de Ecija fueron procesados. En 1511 su abuelo Diego de Cetina fue presentado como testigo por el platero Juan de la Plata y «dize en su deposicion que es converso». Su padre Isidro de la Muela reconoció que era converso durante el proceso que el tribunal de la Inquisición siguió en 1526 contra el entallador Francisco de Coca.

$A E A, \mathrm{LXXV}, 2002,300$, pp. 407 a 446 
declaración, en la que parece ser que mintió, tiempo después él también sería conducido ante el tribunal de la Inquisición ${ }^{3}$.

En efecto, seis años más tarde, exactamente el 13 de septiembre de 1577, el licenciado Vallestero, promotor fiscal del Santo Oficio, mandó que le prendieran y le llevaran a la cárcel de la Inquisición. Tomó esta medida porque consideraba que juro falsamente diziendo que el dicho Cetina era cristiano viejo. Asimismo en el transcurso del proceso el licenciado Vallestero dijo que Tomás Pérez era descendiente deudo y pariente de judios condenados y reconcilia$d o s^{4}$ y que por eso había declarado a favor de Cetina.

El tribunal de la Inquisición de Cuenca, juzgando a Tomás Pérez, cumplía con una orden que le había llegado del Concejo del rey, fechada en Madrid en $1572{ }^{5}$ y que afectaba a todos aquellos descendientes de judíos que con tal de ir a las Indias habían mentido a los señores inquisidores así como también a los testigos que con falsas declaraciones les habían ayudado en su objetivo.

El 17 de septiembre de 1577, Tomás Pérez fue llevado a declarar; solamente habían transcurrido cuatro días desde que había sido prendido. Dijo que tenía 58 años poco mas o menos, que era vecino de Cuenca y que avra que vive y reside en ella quarenta años poco mas o menos sin aver hecho ausencia della sino es aver hecho algunos caminos que se le an ofrecido. Tenía su casa en el barrio de Santa Cruz ${ }^{6}$.

Cuando se preguntó a Tomás Pérez acerca de su familia dijo que su madre se llamaba Juana Pérez y que ignoraba quien había sido su padre ${ }^{7}$. De los cuatro hermanos que tuvo, únicamente Miguel, que en esa fecha ya había fallecido y que como él había llevado el apellido de la madre, también fue bordador ${ }^{8}$.

Asimismo informó a los señores inquisidores que estaba casado con María de la Cruz y que tenía nueve hijos ${ }^{9}$, de los cuales, sólo uno, Juan, que en esa fecha estaba ya casado y trabajaba en Cuenca en donde estaba avecindado, había seguido sus pasos y se dedicaba al arte del bordado.

${ }^{3}$ En 1561 Tomás Pérez había estado ya ante el tribunal de la Inquisición, pero en esta ocasión fue para acusar a un colega suyo, Alonso Muñoz, de que estaba casado con tres mujeres, las cuales vivían en diferentes ciudades. En su declaración se mencionan los nombres de los bordadores Francisco de Tamayo, en cuyo taller trabajaba Tomás Pérez, Dionisio Sánchez, Gabriel de Tamayo y Bartolomé del Castillo.(ADC, Inquisición, leg. 782, n. ${ }^{\circ} 2526$ ).

${ }^{4}$ Tomás Pérez dijo que conocía a Cetina desde que su hija Ana se casó con Francisco de Cetina, y de ello hacía doce años.

${ }^{5}$ Los señores del concejo de su magestad de la sancta general Inquisicion escita a los señores inquisidores de la Inquisicion de Cuenca. Reverendos señores porque en consejo sea tenido relacion que en algunos lugares de ese distrito algunas personas que notoriamente son descendientes de generacion de judios an fecho e fazen ynformaciones ansi para pasar a Yndias como para otros efectos en las quales pruevan ser cristianos viejos limpios de toda raça de judios e moros ha parescido que de aqui adelante esteis señores advertidos desto para que haziendo los tales hijos e nietos o descendientes de condenados y reconciliados las dichas ynformaciones falsas procedais contra ellos y los testigos que depusieren en ellos y ansi mismo procedereis contra los que las obieren hecho guarde Nuestro Señor vuestras reverendas personas en Madrid a diez y seis de junio de mill y quinientos y setenta y dos años.

${ }^{6}$ Era propietario de una casa en la calle de la Zapatería que alquilaba. Sabemos que el 28 de agosto de 1568 Gregorio Resoca renovó por otro año el alquiler de la casa y se comprometió a pagar a Tomás Pérez 99 reales de plata. (AHPC, Gines de Gumiel, 1568-69 (220), fol.22). En esta casa el carpintero Francisco de la Rambla había realizado unas obras en 1555.(M.' Luz Rokiski Lázaro, Arquitectura del siglo xVI en Cuenca. Arquitectos, canteros y carpinteros, Excma. Diputación Provincial de Cuenca, Cuenca, 1989, p. 395).

7 Tomás Pérez contó que «no sabia dezir de cierto quien fue su padre porque su madre deste fue desposada con un Garcia de Salamanca y despues tubo amistad con un clerigo vezino desta ciudad que se llamaba Gabriel de Huermezes(al margen: penitenciado) y que su madre se llamaba Juana Perez natural de Poyatos y que este quedo muy pequeño quando los dichos Garcia de Salamanca y Gabriel de Guelmedes murieron y que no pudo entender qual dellos fuese su padre deste porque de ambos a dos la dicha su madre hubo hijos y este los conocio a entramos y que la dicha su madre nunca le dixo que quien era su padre de los susodichos porque este se aparto della siendo muchacho y nunca mas bolvio a su compañia porque se caso con un labrador de Torrejonzillo que se llamaba Andres de Poyatos.

${ }^{8}$ Sus otros hermanos fueron Diego Pérez, que era sastre; Elena Pérez, que contrajo matrimonio con el sastre Diego de Huesca y Luis de Guelmedes, que fue clérigo.

${ }^{9}$ Diego, Luis, Juan, Cristóbal, Sebastián, Tomás, Ana, Juan y Elena. 
En el transcurso de su declaración Tomás Pérez afirmó que se consideraba un buen cristiano y que estaba en el cavildo de cavalleros y hijosdalgos de esta ciudad.

Entre los testigos que presentó Tomás Pérez aparecen dos bordadores, Juan Pérez y Juan de Carabias, los cuales, el 20 de diciembre de 1577, firmaron sus declaraciones. Ambos coincidieron al afirmar que Tomás Pérez era una buena persona.

Juan Pérez, que estaba avecindado en Cuenca y que cuando prestó declaración tenía quarenta y cinco o quarenta y seis años poco mas o menos, dijo que tiene a Tomas Perez por hombre honrado de buena vida e fama e buen cristiano ... y que le tiene por pobre y que padece nescesidad y sabe que tiene muchos hijos y que tiene tres varones por casar. Juan Pérez fue un afamado artífice. Tenemos noticia de que entre los años 1569 y 1579 hizo para la iglesia parroquial de Fresneda de Altarejos un frontal y un terno de terciopelo carmesí, que se componía de dos dalmáticas, una casulla y una capa pluvial ${ }^{10}$. Asimismo alrededor de 1572 realizó otro terno, en esta ocasión de damasco blanco, para la iglesia parroquial de Carrascosa del Campo ${ }^{11}$.

Juan de Carabias ${ }^{12}$, que también era vecino de Cuenca y contaba sesenta y cinco años de edad, declaró que conocía a Tomás Pérez desde hacia treinta y un años y que en su opinión era un buen cristiano e hizo hincapié en que vivía con grandes dificultades económicas. De Carabias sabemos que bordó una capa negra e hizo una capa de chamelote de frio para la iglesia parroquial de Gascueña ${ }^{13}$.

Tras oír las declaraciones de Tomás Pérez y de sus testigos los inquisidores le mandaron reprehender y que sea reprehendido en la sala e audiencia deste Santo Oficio e oyga la misa que en el se dixere estando en cuerpo sin cinto ni bonete y con una bela de cera encendida en las manos y no se humille sino fuese a la elevation del Santisimo Sacramento mas le peniamos en dos mill maravedies ... y le prohivimos y mandamos daqui adelante no dira dicho ninguno en lo tocante a la limpieça y calidad de ninguna persona e linaje sin licencia deste Santo Oficio.

María Luz RoKisKi LÁzaro

Escuela Técnica Superior de Arquitectura de Madrid

${ }_{10}$ ADC, Sección Parroquias, Libro de fábrica de la iglesia de Fresneda de Altarejos, n. ${ }^{\circ} 318$, fols. 29v, 43, 83, 98v, 162v, 177

${ }^{11}$ M. ${ }^{a}$ Luz Rokiski Lázaro, Documentos para el estudio de la arquitectura en el siglo xvi, Real Academia de Bellas Artes de San Fernando, Madrid, 1988, pág. 46.

12 A principios del siglo xvil trabajó en Cuenca un bordador llamado Jerónimo de Carabias, que tal vez fuera hijo de Juan de Carabias.(M. ${ }^{a}$ Luz Rokiski Lázaro, «Noticias documentales sobre bordadores que trabajan en Cuenca a principios del siglo XVII», Boletín de Amigos del Archivo Histórico Provincial de Cuenca, n. ${ }^{\circ}$ 0, 1966, pp. 27-29).

13 15-octubre-1553. Otrosy mando el dicho señor visitador al mayordomo nuevo de la dicha yglesia que haga hazer una capa negra de dicho anascote de seda para los defuntos con su cenefa de terciopelo negro bordada de hilo de oro con sus calaveras la qual haga Juan de Caravias bordador vecino de Cuenca y no suba la cenefa de valor de veynte ducados e que el mayordomo no haga lo contrario so pena de seys ducados para la dicha yglesia. 29- enero-1556. Se le descargan ocho mill trescientos cincuenta y seis maravedies y medio que pago a Carabias bordador vecino de Cuenca por razon de la capa de chamelote de frio que hizo para la dicha yglesia. (ADC, Sección Parroquias, Libro de fábrica de la iglesia de Gascueña, 1529-1566, sig. 1047, fols. 135, 141v).

AEA, LXXV, 2002, 300, pp. 407 a 446 